\title{
Studies on Preparation and Evaluation of Soluble 1:1 Stoichiometric Curcumin Complex for Colorectal Cancer Treatment
}

\author{
Jamal Moideen Muthu Mohamed ${ }^{1, *}$, Fazil Ahmad², Ali Alqahtani ${ }^{3}$, Taha Iqahtani, \\ Venkatesan Krishna Raju ${ }^{3}$ and M Anusuya ${ }^{1}$
}

\author{
${ }^{1}$ College of Pharmacy, Shri Indra Ganesan Institute of Medical Science, Tiruchirappalli 620012, \\ Tamil Nadu, India \\ ${ }^{2}$ Department of Anesthesia Technology, College of Applied Medical Sciences in Jubail, \\ Imam Abdulrahman Bin Faisal University, Jubail, Saudi Arabia \\ ${ }^{3}$ Department of Pharmacology, College of Pharmacy, King Khalid University, Guraiger, \\ Abha 62529, Saudi Arabia
}

('Corresponding author's e-mail: jmuthumohamed@gmail.com)

Received: 6 December 2019, Revised: 31 July 2021, Accepted: 6 August 2021

\begin{abstract}
This study investigates the complex of curcumin $(\mathrm{CMN})$, which has enhanced solubility and hence, higher cytotoxicity compared to free CMN. Insilco molecular modelling and phase solubility (PS) studies were performed with the drug and carriers for interaction. The complex was characterized by in vitro drug release, FT-IR, PXRD, TGA, DSC, SEM, DLS, and functionalized dyeing test. The result showed that the CMN-PEG6000 complex produced significant properties of solubility ( $\approx 190$ folds) and dissolution ( $80.68 \%$ at $30 \mathrm{~min})$, with stability constants equivalent to 309 and $377 \mathrm{M}^{-1}$ at 25 and $37{ }^{\circ} \mathrm{C}$, respectively. It exhibited $\mathrm{A}_{\mathrm{L}}$ type of isotherm indicating 1:1 stoichiometry. The result from the in vitro cytotoxicity showed that $50 \%$ inhibition $\left(\mathrm{IC}_{50}\right)$ was achieved on the $\mathrm{SW} 480$ and Caco-2 cells at an amount of complex that was considerably lesser than free CMN. Apoptosis study showed that the cells underwent cell death mainly by apoptosis with a small number by necrosis.
\end{abstract}

Keywords: Curcumin, Colorectal cancer, MTT assay, Hoechst staining, Functionalized dyeing test

\section{Introduction}

Primarily, colorectal cancer $(\mathrm{CRC})$ is the $3^{\text {rd }}$ most common cancer in men, the $2^{\text {nd }}$ most common in women, and the $3^{\text {rd }}$ highest cause of death worldwide especially, in developed countries that account for $60 \%$ of all CRC cases. The risk factors of CRC include colon polyps, long-standing ulcerative colitis, and hereditary family history, and it is most often diagnosed in people aged 65 - 74 [1].

Several studies have found that curcumin $(\mathrm{CMN})$ shows a wide range of pharmacological activities and has been considered as one of the most chemopreventive agents that can induce apoptosis in numerous cellular systems. It is also believed to have the potential for defensive impact against an assortment of growths, in particular, in the blood, oral cavity, skin, lung, pancreas, and intestinal tract and the capability to suppress proliferation, transformation, and metastasis of tumours [2]. Many toxicological studies on this drug have indicated that the drug is non-toxic even at high concentrations.

CMN is classified under Biopharmaceutics Classification System (BCS) as class-IV because of its low aqueous solubility $\left(>0.1 \approx 11 \mathrm{mg} / \mathrm{mL}\right.$ at $25^{\circ} \mathrm{C}$ in aqueous buffer $\left.\mathrm{pH}\right)$ and low permeability through intestinal epithelial cells [3]. Despite its benefits, the weak pharmacokinetics of this molecule, that is, its low aqueous solubility, slow dissolution rate, extensive pre-systemic metabolism in the gastrointestinal tract, and poor oral bioavailability restricts its use in human sicknesses.

The enhancement of the solubility of insoluble drugs is an important one among the most challenging undertakings in present-day research. The different physicochemical approaches that have been taken to improve the solubility include the increment in surface area by micronization and nanosizing, generation of the amorphous state, enhancement of wettability of powders, use of prodrugs and salts, the liposome approach [4], and solid dispersion (SD).

The present investigation is aimed at (i) the use of various carriers in the preparation of SD, (ii) the study of thermodynamic parameters including insilico interaction, (iii) characterization of the complex by 
in vitro dissolution, and (iv) enhancing $\mathrm{CMN}$ in anti-cancer activity by modifying its mild cytotoxic profile against the SW480 and Caco-2 cell lines of CRC.

\section{Materials and methods}

\section{Materials}

The following chemicals were purchased: curcumin $(\mathrm{CMN}$, purity $>99 \%$; SRL Pvt. Ltd, Maharashtra, India), PEGs (S.D. Fine Chem. Pvt. Ltd, India), PVP, and BCD (Sigma Aldrich, Bangalore, India) and skimmed milk powder (Aavin, Tamil Nadu co-operative milk product producers, India). All other chemicals and reagents used were of analytical grade.

\section{Studies of phase solubility (PS)}

PS studies were completed by the technique described by Higuchi and Connors [5]. Briefly, this is done by adding an excess amount of $25 \mathrm{~mL}$ aqueous solutions of varying concentrations ( 1 to $15 \%$ ) to the carriers. The Eppendorf tubes containing the solution is placed in a water bath at a constant temperature of 25 and $37 \pm 0.5{ }^{\circ} \mathrm{C}$ for $24 \mathrm{~h}$ until equilibrium is attained, being shaken intermittently at 30 min intervals. Hence, the content filtered by the Millipore membrane filter $(0.45 \mu \mathrm{m})$, is diluted appropriately, and absorbance is observed at $425 \mathrm{~nm}$ with UV-spectrophotometer (Agilent Cary $60 \mathrm{UV}$ Vis Spectrophotometer, USA.). The apparent complexation constant $\left(\mathrm{K}_{1: 1}\right)$ is calculated (Eq. (1)) by utilizing slope and intercept values of the phase solubility curve, where the intercept is the intrinsic solubility of the drug.

$\mathrm{K}_{1: 1}=\frac{\mathrm{S}}{\mathrm{I}(1-\mathrm{S})}$

where, S and I refer to the slope and intercept, respectively; also, the enthalpy change $(\Delta \mathrm{H})$ on determined by the following equation (Eq. (2)).

$\ln \left(\frac{\mathrm{K}_{2}}{\mathrm{~K}_{1}}\right)=\Delta \mathrm{H} \frac{\mathrm{T}_{2}-\mathrm{T}_{1}}{\mathrm{RT}_{2} \mathrm{~T}_{1}}$

where $K_{2}, K_{1}$ and $T_{2}$ and $T_{1}$ refer to the stability constants and corresponding temperatures in Kelvin of 37 and $25{ }^{\circ} \mathrm{C}$, respectively. The change in Gibbs free energy $(\Delta \mathrm{G})$ and entropy $(\Delta \mathrm{S})$ upon complexation/solubilization were computed from the following equations (Eqs. (3) and (4)), respectively.

$\Delta \mathrm{G}=-8.314 \times$ Temperature $\times \ln ($ stability constant)

where $8.314 \mathrm{~J} / \mathrm{mol} \mathrm{K}$ is gas constant

Entropy $=\frac{\text { Enthalphy change-Gibbs free enery }}{\text { Temperature difference }}$

\section{Molecular modelling}

The molecular interaction studies were carried out in BIOVIA discovery studio 2017 (DS) platform by using drug and carriers. The structures were collected from the PubChem and chem book database and converted into a Pdb file, the binding region specified in a sphere based on the functional group present in the carriers [6]. Initially, the grid was generated around the carriers of PEG and BCD with the coordinates of X (8.543), Y (0.652), and Z (0.043), and X (1.152), Y (3.541), and Z (-0.084), respectively. The 10 best conformations were selected to study the interactions. The carriers were docked (C-Docker protocol in DS) around the drug, and finally, the stable complex saved for interaction analysis. CHARMm based algorithm was used for the interaction between the complexes.

\section{Preparation of SD and PM}

The complex of varying compositions (1:3 to 1:7) were prepared by melting (PEG6000 and PEG4000), kneading (SMP), and using the solvent evaporation (BCD and PVP) methods described by Moideen et al. [7]. The prepared SDs were pulverized, sieved (sieve number of 120;150 - $125 \mu \mathrm{m}$ ) and stored at $25^{\circ} \mathrm{C}$ in the desiccator. The physical control blends of the same compositions were prepared by utilizing a mortar and pestle as indicated in the guidelines of geometrical mixing, following by screening.

\section{Aqueous solubility study}

An excess amount of samples (CMN, PM and SD) were added to Milli Q water in a volumetric flask and put in a water bath at a constant temperature of 25 and $37 \pm 0.5^{\circ} \mathrm{C}$ for $24 \mathrm{~h}$ and shaken in 
between at $30 \mathrm{~min}$ intervals [7]. Subsequently, the content was filtered through a Millipore membrane filter $(0.45 \mu \mathrm{m})$, diluted suitably, and the UV absorbance was measured.

\section{In vitro drug release}

The dissolution study was done at $37 \pm 0.5{ }^{\circ} \mathrm{C}$ in $900 \mathrm{~mL}$ of double distilled water at $50 \mathrm{rpm}$ by USP dissolution apparatus II (DS 8000, Lab India, India). The sample was placed into the jar and the time set as 0 . At every $5 \mathrm{~min}$ time interval up to $30 \mathrm{~min}, 5 \mathrm{~mL}$ of the samples were withdrawn and filtered through a Whatman filter paper (pore size $11 \mu \mathrm{m}$ ), and the dissolved amount of CMN was determined spectrophotometrically. A correction, representing the cumulative dilution initiated by replacement of the sample with the same medium to keep up the sink condition, was introduced. Dissolution kinetic studies of the SD were carried out using 0 order, $1^{\text {st }}$ order, and to better characterize the drug release mechanism, Higuchi, Hixson Crowell, Korsmeyer Pappas, and release exponent (n) equation models were applied. Regression coefficient $\left(\mathrm{r}^{2}\right)$ and other factors were calculated to understand the kinetic release pattern from complex [8].

\section{Solid state characteristics}

Solid state characteristics of Fourier transform infrared spectrophotometric analysis (FTIR), powder X-ray diffraction analysis (PXRD), thermogravimetric analysis (TGA), and differential scanning calorimetric analysis (DSC) were performed as described by Muthu et al. and Moideen et al. $[9,10]$.

\section{Dynamic Light Dispersion (DLS) analysis}

Determination of mean particle size (PS), polydispersibility index (PDI), and zeta potential (ZP) of optimized SD and PM was determined through dynamic light scattering technique using Zetasizer [9] (Nano ZS90, Malvern Instruments Ltd., Malvern, UK).

\section{Morphology}

A thin layer of the samples was gold coated $(100 \AA)$ by a sputter coater before the amplifications at a voltage of $5.0 \mathrm{kV}$ [11] were observed. Then, SEM photographs were taken by a scanning zig-zag pattern electron microscope (Carl Zeiss Microscopy Ltd, UK \& SIGMA) operated at an acceleration voltage of $5 \mathrm{kV}$.

\section{Functionalized dyeing experiment}

A simple novel test facilitates the efficient dissolution of a compound (usually colored) in an aqueous medium [12]. Briefly, pictures of the solutions were taken, and then $10 \mathrm{mg}$ of CMN and its SDs (equivalent wt.) were added to $15 \mathrm{~mL}$ of double distilled water followed by sonication for $5 \mathrm{~min}$ and filtration. White linen pieces of material of similar size $\left(8 \times 4.5 \mathrm{~cm}^{2}\right)$ were soaked in the above solution diluted to $50 \mathrm{~mL}$ for $1.5 \mathrm{~h}$.

\section{Cell culture}

The colorectal adenocarcinoma cell lines of SW480 and Caco-2 were obtained from the National Center for Cell Science (NCCS), Pune, India. The cells were cultured in DMEM (Sigma-Aldrich, USA), supplemented with $10 \%$ FBS and $20 \mathrm{~mL}$ of penicillin/streptomycin (1\%) (Hi-media, Mumbai, India) as an antibiotic, at $37{ }^{\circ} \mathrm{C}$ in a humidified atmosphere of $5 \% \mathrm{CO}_{2}$ in a $\mathrm{CO}_{2}$ incubator (Thermo Scientific, USA).

\section{In vitro cytotoxicity study}

The cytotoxicity of the samples against the SW480 and Caco-2 cell lines were estimated utilizing MTT assay [13]. Briefly, the cells were seeded into 96-well culture plates at a cell density of $5 \times 10^{3}$ cells $/ \mathrm{mL}(200 \mu \mathrm{L} /$ well $)$. DMSO solution was used as the solvent control, and after $24 \mathrm{~h}$ of incubation in different concentrations of the complexes, the MTT solution $(5 \mathrm{mg} / \mathrm{mL}, 20 \mu \mathrm{L} / \mathrm{well})$ was added to the media, followed by incubation for a further $4 \mathrm{~h}$ at $37{ }^{\circ} \mathrm{C}$. The obtained purple formazan product was dissolved by adding $100 \mu \mathrm{L}$ of DMSO solution to each well. The absorbance estimations of each well were estimated at $570 \mathrm{~nm}$ utilizing a plate reader (Bio-Rad, iMark, USA). The $\mathrm{IC}_{50}$ value was determined, as the complex concentration is required to reduce the absorbance to half the percentage of that of control.

\section{Apoptosis study}

Apoptotic morphology was investigated by acridine orange (AO) and ethidium bromide (EB) staining $(\mathrm{AO} / \mathrm{EB})$, the double staining method [14] with some modifications. Briefly, the cells treated 
with the $\mathrm{IC}_{50}$ concentration of compounds for $24 \mathrm{~h}$ were harvested and washed with cold PBS. The cell pellets were resuspended and diluted with PBS to a concentration of $5 \times 10^{5}$ cells $/ \mathrm{mL}$, mixed with $25 \mu \mathrm{L}$ of staining solution $(3.8 \mu \mathrm{m}$ of $\mathrm{AO}$ and $2.5 \mu \mathrm{m}$ of EB in PBS) on a clean slide, and quickly analyzed under a fluorescent microscope (Carl Zeiss, Axioscope 2plus, Germany) with UV filter (450 - $490 \mathrm{~nm})$. Three hundred cells for each sample were counted for viable, apoptotic, or necrotic status by staining the nucleus structure, and the membrane integrity and percentage were calculated. Morphological variations were also observed and photographed (400× magnification).

\section{Analysis of cell death by Hoechst staining}

SW480 and Caco-2 cells were cultured in separate 6-well plates and treated with $\mathrm{IC}_{50}$ concentrations of the samples. Control and treated cells were collected after $24 \mathrm{~h}$ of incubation and stained (Hoechst 33258 stain; $\mathrm{mg} / \mathrm{mL}$; aqueous) for $5 \mathrm{~min}$ at room temperature [7]. The fluorescent microscope fitted with a $377-355 \mathrm{~nm}$ filter was used to randomly observe 300 cells with $400 \times$ magnification.

\section{Results and discussion}

\section{PS studies}

This study provided essential data on the impact of the different carriers on the solubility of CMN. A standard linear curve obtained in the concentration ranges from $5.97 \times 10^{-5}$ to $5.7 \times 10^{-4} \mathrm{Mm}$ and $8.14 \times 10^{-5}$ to $7.8 \times 10^{-4} \mathrm{Mm}$ at 25 and $37^{\circ} \mathrm{C}$, respectively (Table 1). These results revealed an $\mathrm{A}_{\mathrm{L}}$ type of phase solubility profile (the solubility of the drug increased linearly as a function of the carrier concentration) caused by the changes in the interaction forces, such as Vander Waals and hydrophobic forces between the CMN and the carriers. The slope of the phase solubility diagram obtained $(>1)$ in all carriers indicated the 1:1 complex stoichiometry. Among all the carriers, PEG6000 and PEG4000 showed the ideal complexation constant in the ranges of 100 to $1000 \mathrm{M}^{-1}$. In contrast, BCD and SMP showed weak interaction with CMN; hence, PVP shown the complex is too strong (PVP $\approx 1033$ and 2081 at 25 and $37{ }^{\circ} \mathrm{C}$ respectively). Iacovino and coworkers showed that the complex does not dissociate freely if the stability constant is greater than $1000 \mathrm{M}^{-1}$ [15]. The $\mathrm{K}_{1: 1}$ was calculated from the slope and intrinsic intercept values of the solubility curves (Figure 1(a) and 1(b)) by plotting the concentration of dissolved $\mathrm{CMN}(\% \mathrm{w} / \mathrm{v})$ against the concentration of the carrier $(\% \mathrm{w} / \mathrm{v})$.

Table 1 Thermodynamic parameters of $\mathrm{CMN}$ with various carriers at 25 and $37^{\circ} \mathrm{C}($ mean $\pm \mathrm{SD}, \mathrm{n}=3)$.

\begin{tabular}{|c|c|c|c|c|c|c|}
\hline Carrier & $\begin{array}{c}\mathbf{T} \\
\left({ }^{\circ} \mathbf{C}\right)\end{array}$ & $\begin{array}{l}\text { Intercept } \\
(\mathrm{Mm})\end{array}$ & $\begin{array}{c}\mathbf{K a} \\
\left(\mathbf{M}^{-1}\right)\end{array}$ & $\underset{(\mathrm{kJ} / \mathrm{mol})}{\Delta \mathrm{G}}$ & $\underset{(\mathrm{kJ} / \mathrm{mol})}{\Delta \mathbf{H}}$ & $\Delta \mathrm{S}(\mathrm{kJ} / \mathrm{mol} \mathrm{K})$ \\
\hline \multirow[t]{2}{*}{ BCD } & 25 & $1.36 \times 10^{-4}$ & $52.62 \pm 2.057$ & $-9.8 \pm 0.076$ & $13.1 \pm 0.464$ & $0.07688 \pm 0.005$ \\
\hline & $\begin{array}{l}37 \\
25\end{array}$ & $\begin{array}{l}1.63 \times 10^{-4} \\
3.74 \times 10^{-4}\end{array}$ & $\begin{array}{c}64.56 \pm 2.947 \\
141.38 \pm 6.842\end{array}$ & $\begin{array}{l}-10.74 \pm 0.076 \\
-12.27 \pm 0.221\end{array}$ & $14.2 \pm 0.762$ & $0.08882 \pm 0.002$ \\
\hline PEG4000 & $\begin{array}{l}37 \\
25\end{array}$ & $\begin{array}{l}6.27 \times 10^{-4} \\
4.61 \times 10^{-4}\end{array}$ & $\begin{array}{c}176.38 \pm 7.874 \\
309.79 \pm 14.814\end{array}$ & $\begin{array}{l}-13.33 \pm 0.234 \\
-14.22 \pm 0.087\end{array}$ & $12.7 \pm 0.567$ & $0.09093 \pm 0.001$ \\
\hline PEG6000 & 37 & $6.78 \times 10^{-4}$ & $377.89 \pm 15.846$ & $-15.30 \pm 0.067$ & & \\
\hline \multirow[t]{2}{*}{ PVP } & 25 & $1.38 \times 10^{-4}$ & $1033.91 \pm 34.067$ & $-17.21 \pm 0.312$ & $44.8 \pm 3.124$ & $0.20812 \pm 0.004$ \\
\hline & 37 & $1.46 \times 10^{-4}$ & $2081.81 \pm 44.168$ & $-19.72 \pm 0.345$ & & \\
\hline \multirow[t]{2}{*}{ SMP } & 25 & $5.43 \times 10^{-5}$ & $9.21 \pm 1.639$ & $-5.51 \pm 0.912$ & $-4.13 \pm 0.081$ & $0.00476 \pm 0.004$ \\
\hline & 37 & $8.14 \times 10^{-5}$ & $8.63 \pm 1.233$ & $-5.65 \pm 0.088$ & & \\
\hline
\end{tabular}

The calculated value of $\Delta \mathrm{G}$ was found to be negative in all carriers, indicating the spontaneity of binding (solubilization), and it increased with a decrease in the concentration of carrier. The calculated value of $\Delta \mathrm{H}$ found to be positive (endothermic) in all the carrier complexes except the solubility system with SMP $(-\Delta H$; exothermic). Similarly, the $\Delta \mathrm{S}$ value in BCD, PEG6000, PEG4000, and PVP system were found to be very high $(7,8,9$, and $20 \mathrm{~J} / \mathrm{mol} \mathrm{K})$, showing that the reaction type is endothermic. 
The stronger binding constant observed at PEG6000 (309 and $377 \mathrm{M}^{-1}$ ) and PEG4000 (141 and 176 $\mathrm{M}^{-1}$ ) at 25 and $37{ }^{\circ} \mathrm{C}$ respectively, could be because the additional contacts offer intermolecular interactions between the solvent molecules. This is expected to control the interaction of the solvent with the heteroatom [16]. The dielectric constant of an aqueous solution of PEG decreases with the increase in concentration; apart from the high solubility of CMN in PEGs (glycol schemes), the hydrophobic interaction (hydrogen bond) plays a more important part in the solubility of the CMN in the long nonpolar part of PEGs. Subsequently, we observed that though PEG4000 has a desired stable complex, it is marginally lesser than PEG6000 because of the low viscosity of PEG4000. The solubility of the CMN complex with BCD is relatively limited because of the latter's limited solubility characteristic and the hydrophobic interaction (the hydrogen bond of CMN with the carbonyl group of PVP) involved between the CMN and PVP [17]. This binding may be an entropy effect - water molecules relatively ordered around exposed nonpolar solute molecules - but when 2 non-polar molecules approach, then the disorganized water molecules increase, which causes a favorable entropy change and free energy of association.
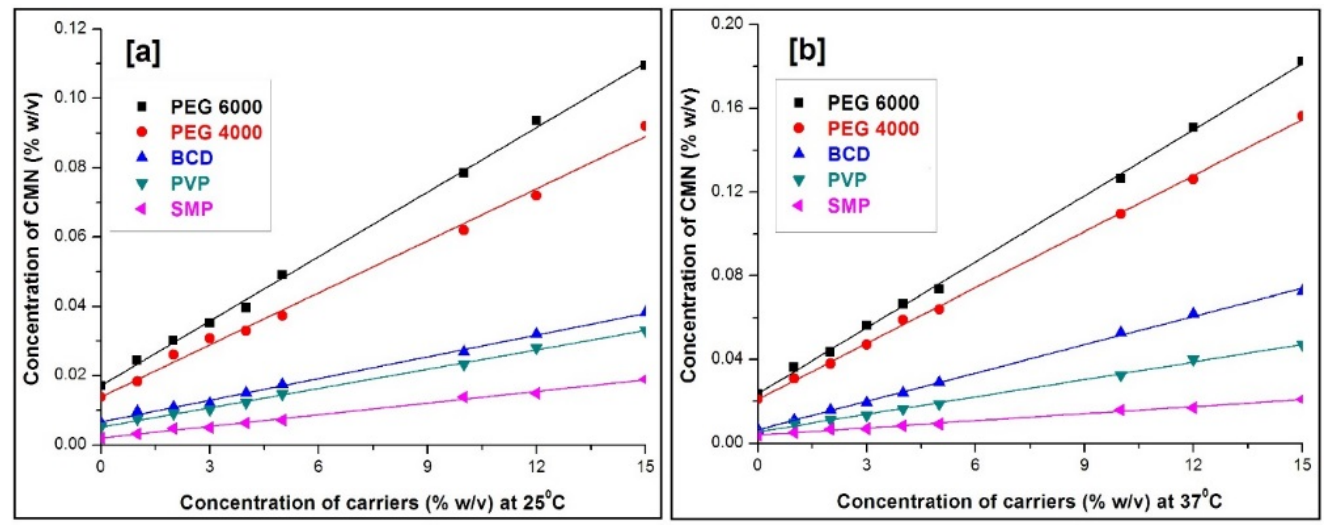

Figure 1 Phase solubility diagram of $\mathrm{CMN}$ in water; at $25^{\circ} \mathrm{C}$ (a) and $37^{\circ} \mathrm{C}$ (b) in the presence of PEG6000, PEG4000, BCD, PVP, and SMP.

An exception was noticed in the case of SMP, where very low $(-\Delta \mathrm{S})$ value $(0.5 \mathrm{~J} / \mathrm{mol} / \mathrm{deg}$.) was obtained because the ligand molecules are more ionized and water molecules much more ordered. The $\Delta \mathrm{G}$ was favoured by $-\Delta \mathrm{H}$ and $\Delta \mathrm{S}$ and spontaneity was ensured by negative $\Delta \mathrm{G}$. The surface active properties and amino acid content of SMP (protein; casein), which acts as an emulsifier and surface active agent, may lead to less interaction with $\mathrm{CMN}$ as the hydrophobic part of the hydrogen group [7].

\section{In silico interaction studies}

Computer modelling of PEG and BCD contributed selectivity to the points of interest of their molecular structure. Insilco interaction studies established and simplified the stability (complex) of the drug and ligand molecules. The perfect molecular modelling for the 1:1 complex of CMN: PEG is shown in Figure 2(i). PEG contains the central ketone group and the hydroxy hydrogen interaction with the ethylene hydrogen region of the $\mathrm{CMN}$ comprising the benzene ring and the methoxy $\mathrm{CH} 3$ hydrogenoxygen group [18] in the distance range of $2.7 \AA$. In addition, the 2 hydrophilic chains of polyoxyethylene (poly (ethylene oxide) are involved in the interaction with the ketone group of CMN at a bond distance of 1.9 - $2.5 \AA$. The optimal hydrogen interactions involved in the CMN/PEG complex were the included in the complete interaction with the ketone group of CMN. A tighter CMN/PEG fit seems to clarify the little changes in enthalpy, and positive changes in entropy were observed in the complex formation, resulting from enthalpy-entropy compensation.

Inadequate complex configurations were attained in the case of $\mathrm{CMN}$ with $\mathrm{BCD}$. The interaction included a partial inclusion of methoxy hydrogen in CMN forming a hydrogen bond interaction with the $\mathrm{OH}$ group oxygen in BCD [19] with a bond distance of $2.7 \AA$, and the ketone group of CMN formed 2 weak hydrogen bonds with a distance of 1.9 - $2.4 \AA$ (Figure 2(ii)), thus, confirming the low tendency of $\mathrm{BCD}$ to complex and revealing a less stable and soluble formulation compared to PEG complex. 

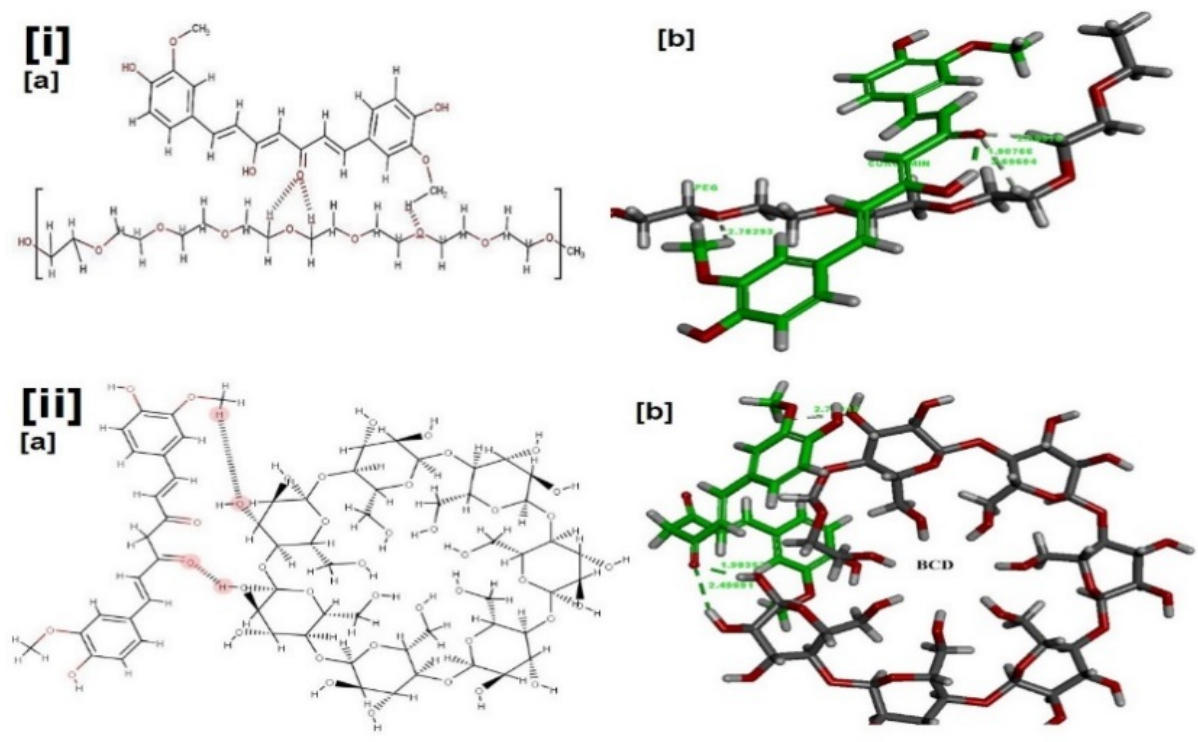

Figure 2 Molecular modeling for the 1:1 complex of CMN: PEG (a); 2D representation of structures of enol form of $\mathrm{CMN}$ on the monomer showing hydrophobic bonding of phenolic OH group (a; i and ii). 3D representation of Dock-pose of enol form of CMN (Green tubes represent the monomer unit of CMN, and Grey tubes represent PEG/BCD; dotted lines indicating thee most important interactions, the distances are mentioned in Å units) (b; i and ii).

Overall, the insilico interaction study results showed that the nonionic PEG forms a better nonbonded interaction with $\mathrm{CMN}$ than $\mathrm{BCD}$. These studies provided a better understanding of complexation with the carrier, and the results matched exactly with the data obtained from PS studies. The overall view on aqueous solubility of $\mathrm{CMN}$ in the $\mathrm{SD}$ was found to increase depending on the concentration of the carrier.

\section{Solubility studies}

The solubility of pure $\mathrm{CMN}$ in distilled water at $37{ }^{\circ} \mathrm{C}$ was found to be $0.004 \mathrm{mg} / \mathrm{mL}$ for $24 \mathrm{~h}$. In PEG6000 and PEG4000 (1:3 to 1:7), the solubility of CMN was found to be enhanced by $\sim 177$ to 203 and $\sim 143$ to 170 -fold, respectively (Table 2). The aqueous solubility is because of higher bonding of hydrogen in the water particles to an electron-rich oxygen atom in the polymer chains of PEGs. Surface properties enhance the wettability by diminishing the surface tension of the vehicle employed so that the drug molecules can penetrate into an aqueous environment [20]. The CMN-BCD inclusion complex demonstrated vivid enhancement of solubility up to 72-fold, which was attributed to the cyclodextrin complex. The complex system with PVP and SMP revealed complexes optimized for solubility 25 to 30 fold and 5 to 8 -fold, respectively. The CMN-SMP system's optimization was attributed to amino acid impact. The general view on aqueous solubility of CMN in the SD was observed to increase depending on the concentration of the carrier.

Table 2 Aqueous solubility data of CMN-SD (mean $\pm \mathrm{SD}, \mathrm{n}=3$ ).

\begin{tabular}{|c|c|c|c|c|c|}
\hline \multicolumn{6}{|c|}{$\begin{array}{c}\text { Aqueous solubility }{ }^{\dagger} \\
(\mathrm{mg} / \mathrm{mL})\end{array}$} \\
\hline D:C ratio* & $1: 3$ & $1: 4$ & $1: 5$ & $1: 6$ & 1:7 \\
\hline \multicolumn{2}{|c|}{ Pure $\mathrm{CMN}$ at $37^{\circ} \mathrm{C}$} & & $0.004 \pm 0.0003$ & & \\
\hline PEG6000 & $0.6734 \pm 0.014$ & $0.7132 \pm 0.015$ & $0.7458 \pm 0.016$ & $0.7720 \pm 0.021$ & $0.7926 \pm 0.021$ \\
\hline PEG4000 & $0.5924 \pm 0.035$ & $0.6172 \pm 0.031$ & $0.6501 \pm 0.025$ & $0.6710 \pm 0.022$ & $0.6812 \pm 0.032$ \\
\hline BCD & $0.2471 \pm 0.031$ & $0.2698 \pm 0.163$ & $0.2779 \pm 0.022$ & $0.2876 \pm 0.028$ & $0.2917 \pm 0.027$ \\
\hline PVP & $0.1012 \pm 0.031$ & $0.1056 \pm 0.020$ & $0.1132 \pm 0.017$ & $0.1189 \pm 0.031$ & $0.1212 \pm 0.032$ \\
\hline SMP & 0.0235 & $0.0267 \pm 0.015$ & $0.0277 \pm 0.016$ & $0.0304 \pm 0.020$ & $0.0331 \pm 0.021$ \\
\hline
\end{tabular}

* Drug: carrier ratio. 


\section{In vitro dissolution studies}

The mean dissolution curves of $\mathrm{CMN}$ and $\mathrm{SD}$ are presented in Figure 3. It is evident that the dissolution rate of pure CMN was very slow $(1.62 \%)$ at the end of $30 \mathrm{~min}$ because of its high hydrophobicity that makes the powder float on the dissolution medium (distilled water) and prevents contact with the bulk of the solution. The dissolution rate of CMN-SD with their respective carriers demonstrated high burst release $(15-74 \%)$ in the initial $5-6$ min showing proper complex development with the carrier or the amorphous/crystal lattice. After burst release, the low amount of drug was released in the steady state, which is seen at all PM and SDs. In CMN-PEG6000 (1:5) framework, $80.68 \%$ of the drug was released at the end of 30 min with the initial burst release of $74.39 \%$ whereas the release of 70 $\%$ at $5 \mathrm{~min}$, and then, $78 \%$ at $30 \mathrm{~min}$ observed in the PEG4000 SD. This may be owing to the metastable supersaturation of the drug in the concentrated wet carrier during dissolution [21]. The change of dissolution rate could be because of the decrease in particle size, while the drug dispersed in the molten carrier (appearance of the glassy matrix of the drug), and the sudden solidification of the carrier. Hence, CMN-SD (PEG) released a more significant amount compared with rest of the carriers. The in vitro release demonstrated that after the burst release, a constant rate release profile was observed with all SDs. These may occur due to the metastable supersaturation of the drug in the wet carrier matrix during dissolution. Apart from non-ionic attributes, viscosity plays a part in the dissolution of the drug by delaying the contact of the drug with the dissolution medium.

Rapid dissolution of the drug, if there should be an occurrence of PM, might be clarified as an in situ complex development prompting subsiding interfacial tension. It is notable that the hydrophilic carriers PVP and BCD increase the wettability and spread ability of the drug by decreasing aggregation in the readily soluble state. PVP is a hydrophilic carrier and, as a result of the improved release and its hostileplasticizing action, the viscosity of the binary system increases, which in turn diminishes the dispersion of the drug molecule significantly to help form the crystal lattice. The improved dissolution of the drug in SMP demonstrated stronger interaction. The presence of proteins and amino acids influenced the solubility of the drug by forming an inclusion complex [22].
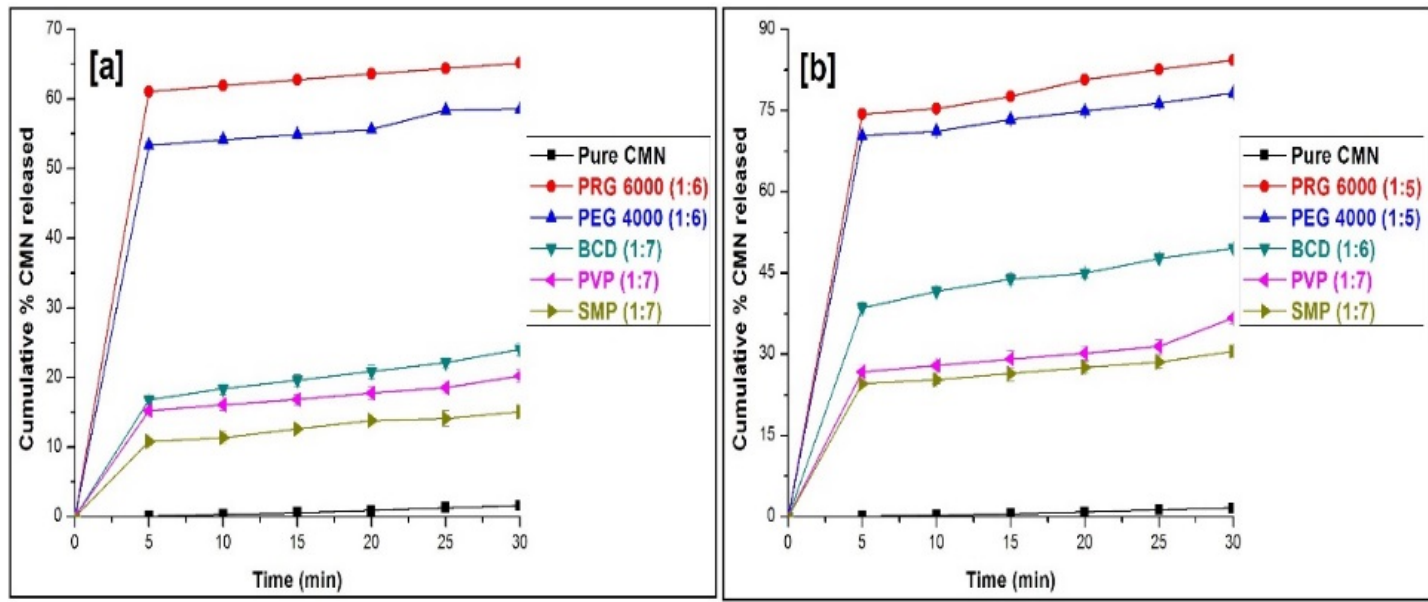

Figure 3 In vitro release of CMN from PM (a) and SD (b). (Mean $\pm \mathrm{SD}, \mathrm{n}=3$ ).

The results obtained from the SD of BCD, PVP, and SMP were not satisfactory in comparison to other carriers (Figure 3). Hence, PEG showed an enhanced dissolution profile up to the proportion of 1:5, and then decreased at the higher percentage of the carrier. Collectively, increased dissolution was a function of carrier concentration. In CMN-SD with BCD, PVP, and SMP the dissolution obtained was not satisfactory in comparison to other carriers. The result showed the limited dissolution rate of BCD, PVP, and SMP might be because of incomplete amorphization of the drug particles compared with the pure drug powder.

In order to determine the model best depicting the pattern of drug release, the calculated value of the data has been substituted with 0 order $\left(r^{2}=0.471-0.597\right), 1^{\text {st }}$ order $\left(r^{2}=0.579-0.660\right)$, Higuchi $\left(r^{2}=\right.$ 0.916 - 0.988), Korsmeyer-Peppas $\left(r^{2}=0.866-0.970\right)$, and Hixon Crowell Release $\left(r^{2}=0.963-0.990\right)$. The release exponent (n) obtained from Korsmeyer-Peppas was in the range of $0.058-0.134$ (Table 3). 
Table 3 In vitro release kinetics of $\mathrm{CMN}$ with various carriers (mean $\pm \mathrm{SD}, \mathrm{n}=3$ ).

\begin{tabular}{ccccccc}
\hline & \multicolumn{7}{c}{ Correlation coefficient $\left.\mathbf{r}^{\mathbf{2}}\right)$} \\
\hline Carrier & Zero order & First order & Higuchi & $\begin{array}{c}\text { Hixon } \\
\text { Crowell }\end{array}$ & $\begin{array}{c}\text { Korsmeyer- } \\
\text { Peppas }\end{array}$ & $\begin{array}{c}\text { Release } \\
\text { exponent (n) }\end{array}$ \\
\hline PEG6000 (1:5) & $0.495 \pm 0.12$ & $0.660 \pm 0.28$ & $0.957 \pm 0.21$ & $0.983 \pm 0.14$ & $0.899 \pm 0.15$ & $0.073 \pm 0.38$ \\
PEG4000 (1:5) & $0.471 \pm 0.22$ & $0.579 \pm 0.19$ & $0.965 \pm 0.23$ & $0.989 \pm 0.23$ & $0.912 \pm 0.15$ & $0.058 \pm 0.18$ \\
BCD (1:6) & $0.587 \pm 0.16$ & $0.657 \pm 0.15$ & $0.988 \pm 0.31$ & $0.990 \pm 0.16$ & $0.970 \pm 0.33$ & $0.136 \pm 0.43$ \\
PVP (1:7) & $0.565 \pm 0.31$ & $0.598 \pm 0.19$ & $0.938 \pm 0.24$ & $0.978 \pm 0.23$ & $0.886 \pm 0.32$ & $0.115 \pm 0.32$ \\
SMP (1:7) & $0.597 \pm 0.34$ & $0.628 \pm 0.23$ & $0.916 \pm 0.16$ & $0.963 \pm 0.31$ & $0.866 \pm 0.25$ & $0.134 \pm 0.43$ \\
\hline
\end{tabular}

The in vitro release kinetics was the best-fit release mechanism revealed by the higher correlation from Hixon Crowell (cubic root of the \% drug remaining versus time). It is known that the rate of release is controlled by the drug particles, and not by diffusion [23]. This model has been utilized to show that the release profile may reduce the surface of the drug particles during the dissolution. The release exponent ' $n$ ' did not obey this model, so it could be a poly-dispersible product.

\section{Solid state characteristics}

FTIR

FTIR spectrum of CMN, the carriers, and its PM and SDs are shown in Figure 5, where CMN shows the number of characteristic bands representing $\mathrm{O}-\mathrm{H}$ stretching (alcohol, 3324.68, and $3015.16 \mathrm{~cm}^{-}$ $\left.{ }^{1}\right), \mathrm{C}=\mathrm{O}$ stretching $\left(1742.37 \mathrm{~cm}^{-1}\right), \mathrm{C}=\mathrm{C}$ stretching (alkenes, $1629.55 \mathrm{~cm}^{-1}$ and aromatic, 1597.73 and $\left.1507.1 \mathrm{~cm}^{-1}\right)$, C-H bending $\left(1426,1,1371.14,960.377\right.$ and $\left.810.92 \mathrm{~cm}^{-1}\right)$, and stretching vibration [24].

The characteristic bands of both PEG6000 and PEG4000 show that O-H stretching vibration (3479.92 and $3438.46 \mathrm{~cm}^{-1}$ ) corresponding to PEGs disappeared and $\mathrm{C}=\mathrm{O}$ stretching vibration (1642.09 and $1645.95 \mathrm{~cm}^{-1}$ ) owing to CMN found that reduced intensity with PM and SD, suggested the formation of the complex by hydrogen bonding. The single peak observed at 2876.31 and $2874.24 \mathrm{~cm}^{-1}(\mathrm{C}-\mathrm{H}$ stretching) may be the alternative complexing site of the drug with the carrier (Figure 4(a)). Similarly, SD showed the absence of the N-H stretching band at $3343 \mathrm{~cm}^{-1}$, suggesting the intermolecular hydrogen bonding between the drug and the carrier.

A broad absorption peak at $3387.35 \mathrm{~cm}^{-1}$ (O-H stretching vibration) and $2922 \mathrm{~cm}^{-1}$ (for C-H stretching vibration) were characteristic of BCD. From the structure of BCD, it can be assumed that the possible interaction could occur between the hydroxyl group (proton donor) and carbonyl group (proton acceptor) of the drug and the carriers, respectively [25].

The characteristic bands of PVP observed at $3450.99,2922.59,1662.34$ and $934.34 \mathrm{~cm}^{-1}$ corresponding to $\mathrm{O}-\mathrm{H}$ stretching, $\mathrm{C}-\mathrm{H}$ stretching, $\mathrm{C}=\mathrm{C}$ stretch, $\mathrm{C}-\mathrm{O}$ stretching and $\mathrm{C}-\mathrm{H}$ bending vibrations. In PM, the characteristics of the drug were prominent and large single $\mathrm{O}-\mathrm{H}$ stretching vibration peak observed at 3450,2922 , and $1662.59 \mathrm{~cm}^{-1}$ in SD indicated that the interaction between the $\mathrm{O}-\mathrm{H}$ group of the drug and carbonyl groups of PVP showed slightly altered peak position. $\mathrm{C}=\mathrm{O}$ stretching vibration attributed to $\mathrm{CMN}$ disappeared in SD, suggesting its interaction with the carrier because of hydrogen bonding. The characteristic bands of SMP observed at $3460.63 \mathrm{~cm}^{-1}$, and the band at 1662.34 $\mathrm{cm}^{-1}$ (alkenes) indicated the amorphous nature of the product. Some variation in the drug's peak corresponding to $\mathrm{O}-\mathrm{H}$ stretch and $\mathrm{C}-\mathrm{H}$ stretch was observed in both $\mathrm{PM}$ and SD of SMP. The disappearance of the peak owing to $\mathrm{C}=\mathrm{O}$ group of the drug suggests that some interaction takes place (Figure 4(b)).

\section{PXRD}

The XRD patterns of CMN exhibited sharp peaks (due to the presence of a crystalline form of the drug) at $2 \theta$ of $8.98^{\circ}, 17.38^{\circ}$ and a series of tiny peaks at $23.48^{\circ}, 24.72^{\circ}, 25.68^{\circ}, 26.22^{\circ}$, and $27.5^{\circ}$ (Figure 4(c)). The carrier typical peaks such as PEG6000 ( $2 \theta$ of $19.38^{\circ}, 23.54^{\circ}$ and $\left.27.08^{\circ}\right)$ and PEG4000 (20 of $19.46^{\circ}, 23.62^{\circ}$ and $27.28^{\circ}$ ) indicate the crystalline domain within the amorphous polymeric material [25]. In contrast, BCD, PVP and SMP showed amorphous characteristics because of the lack of complete stereo uniformity and the presence of the large lateral group in the carrier.

In PEGs, the observed result showed that the amorphous nature was prominent in both PM because of the reduced intensity. That a large amount of the drug was dissolved in a solid carrier matrix in its amorphous structure was confirmed by various characteristic peaks of the SDs signifying the conversion 
of the crystalline form of CMN to the amorphous form in the SD. Both PM and SD of BCD, PVP and SMP exhibited the amorphous form with reduced intensity at $2 \theta$ of $8.98^{\circ}$ and $17.38^{\circ}$ when compared with that of crystalline CMN [26]. The amorphous nature of the carriers was established at SD entirely in their respective diffractograms (Figure $\mathbf{4}(\mathbf{d})$ ).
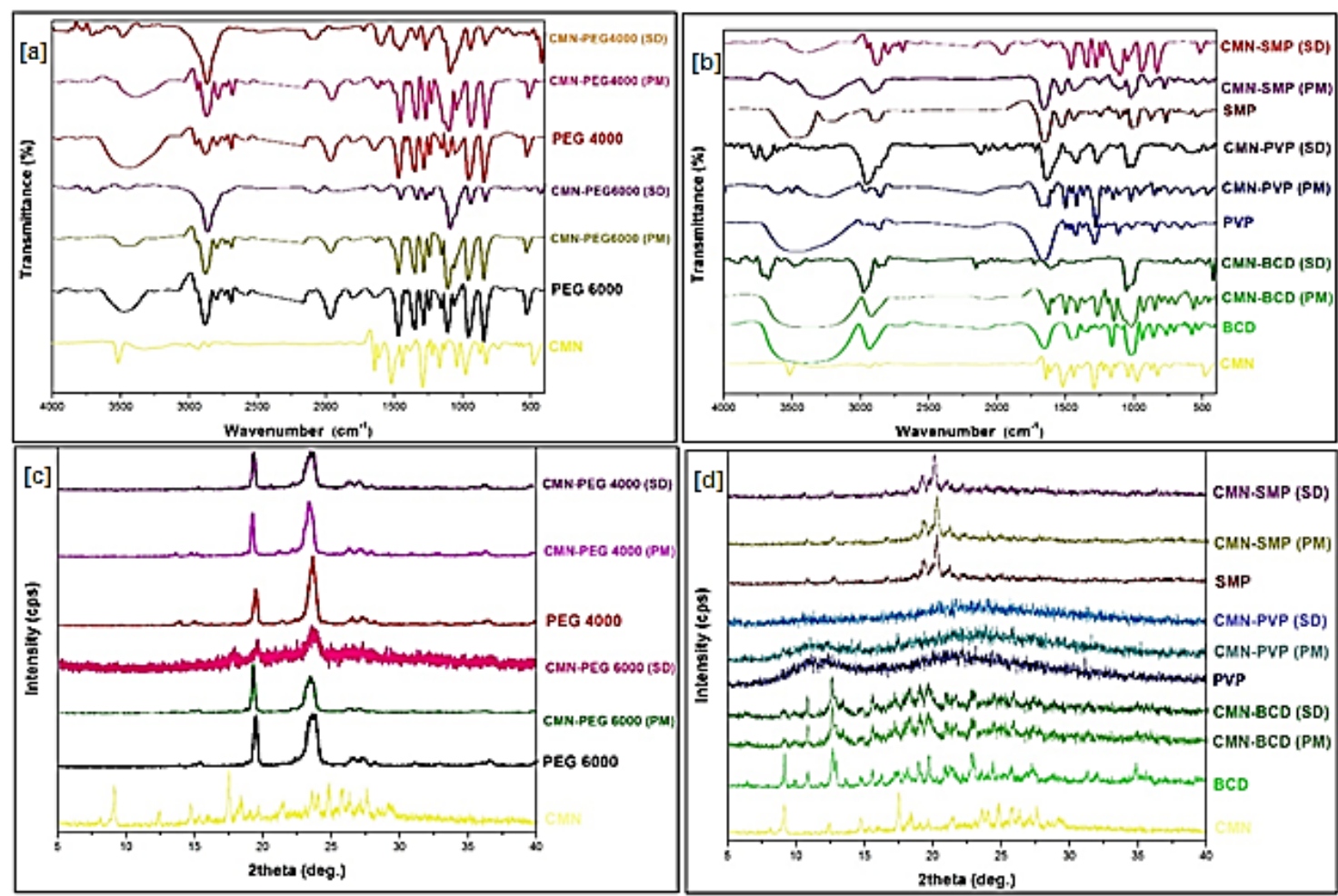

Figure 4 FTIR spectrum and PXRD pattern; CMN, PEG6000, CMN-PEG6000 (PM), CMN-PEG6000 (SD), PEG4000, CMN-PEG4000 (PM), CMN-PEG4000 (SD) (a and c) and CMN, BCD, CMN-BCD (PM), CMN-BCD (SD), PVP, CMN-PVP (PM), CMN-PVP (SD), SMP, CMN-SMP (PM), CMN-SMP (SD) (b and d).

\section{TGA}

The thermal decomposition of CMN, PEG6000, PEG4000 and its corresponding PM and SDs was studied by TGA, and the thermogram is shown in Figure 5(a). The CMN mass loss began at $101{ }^{\circ} \mathrm{C}$, and the complete weight loss was observed at $530^{\circ} \mathrm{C}$. There are 3 areas of weight loss that has been seen with PEGs - weight loss in the range of (i) $40-140{ }^{\circ} \mathrm{C}$, (ii) $250-465{ }^{\circ} \mathrm{C}$; and (iii) complete weight loss observed above $523^{\circ} \mathrm{C}$. Hence, the PM of PEGs decomposes between 270 and $532{ }^{\circ} \mathrm{C}$. Similarly, the SD from PEGs decomposes in the range from 290 to $535^{\circ} \mathrm{C}$. The thermal tratment of the various carries showing the differences in thermal decomposition of CMN, PM, and SDs are insignificant; we could confirm that there were no chemical interactions in the SD complex. These differences between the PM and the SD during this stage (mass loss) might be a host-guest interaction that could restrict the movement of the molecules of CMN. The physiochemical properties, such as melting, boiling, and sublimation points, altered when the guest molecules interacted with the host molecules in PM. In a complex system of PEG6000 and PEG4000, the complete disappearance of the endothermic peak corresponding to $\mathrm{CMN}$ could be due to the release of water molecules or the complete conversion to the amorphous form or dissolution of the crystalline form into the molten carrier. The differences in thermal decomposition of PM and SDs are insignificant; we could confirm that there were no chemical interactions of the complex [27]. 


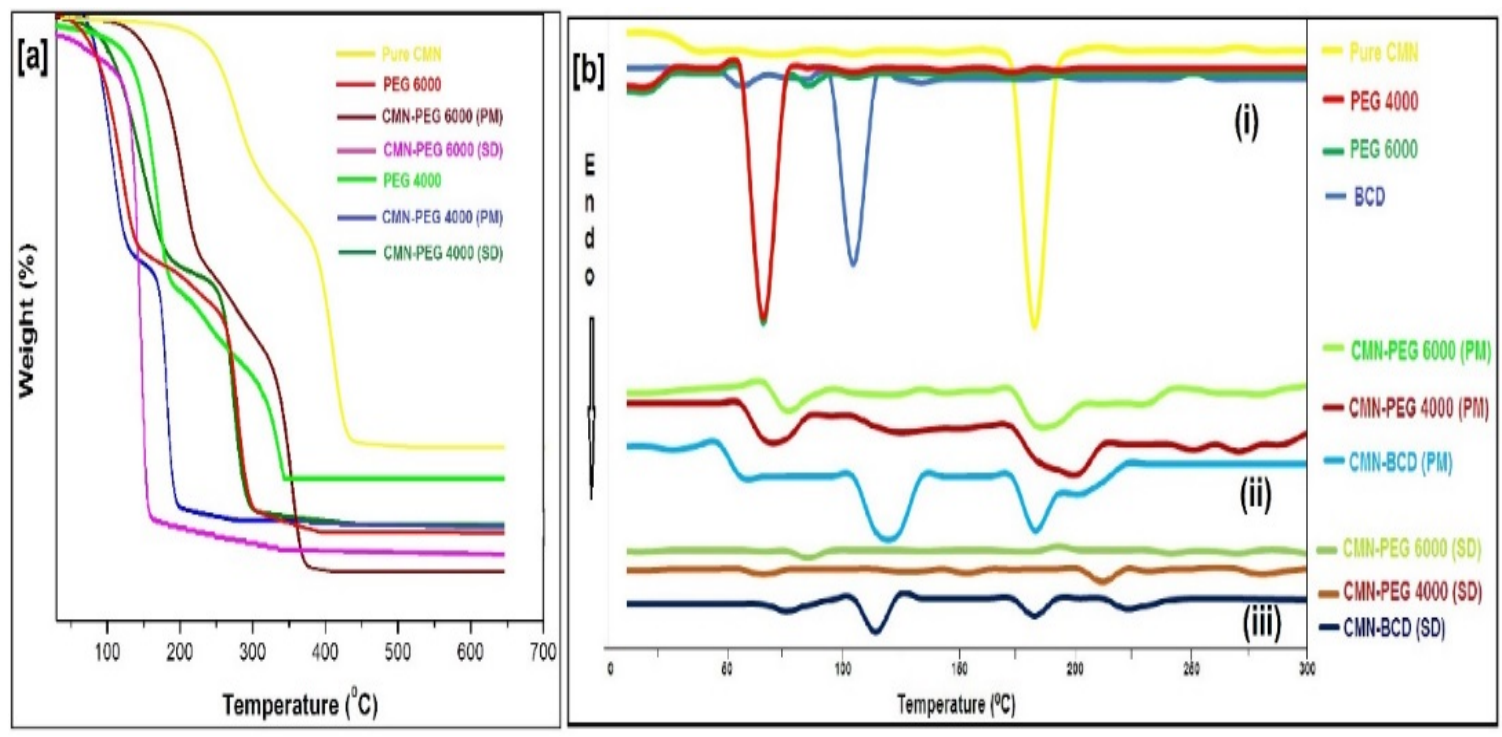

Figure 5 TGA curve of Pure CMN, PEG6000, CMN-PEG6000 PM (1:6), CMN-PEG6000 (SD) (1:5), PEG4000, CMN-PEG4000 PM (1:7) and CMN-PEG4000 (SD) (a) and DSC thermogram of Pure CMN, PEG4000, PEG6000, BCD, CMN-PEG6000 PM (1:6), CMN-PEG4000PM (1:5) and CMN-BCD PM (1:7), CMN-PEG6000 SD (1:5), CMN-PEG4000 SD (1:5) and CMN-BCD SD (1:7) (b).

\section{DSC}

The DSC thermograms of CMN $\left(179.8^{\circ} \mathrm{C}\right)$, PEG6000 $\left(61.1^{\circ} \mathrm{C}\right)$, and PEG4000 $\left(59.7^{\circ} \mathrm{C}\right)$, and BCD (between 60 and $120{ }^{\circ} \mathrm{C}$ due to the loss of water) exhibited endothermic peaks, which conforms with the reported data as shown in Figure 5(b) (i). The physiochemical properties, such as melting, boiling, and sublimation points, altered when the CMN interacted with the carrier in the PM as shown in Figure 5(b) (ii).

In $\mathrm{SD}$ of PEGs, the complete disappearance of the endothermic peak corresponding to $\mathrm{CMN}$ is because of the release of water molecules or conversion into the full amorphous form or dissolution of the crystalline form into the molten carrier. A small broad peak near $208^{\circ} \mathrm{C}$ observed in the SD of CMN$\mathrm{BCD}$ with reduced intensity may correspond to the melting of $\mathrm{CMN}$ at a considerably higher temperature [28] and indicated a reduction in the crystallinity of the drug (Figure 5(b) (iii)).

\section{SEM}

The SEM image in Figure 6(i) supports the surface morphologies of pure CMN (a), PEG6000 (b), and its PM (1:6) (c) and SD (1:5) (d). CMN appeared as a characteristic prism-surfaced crystalline structure with average particle size shown as $15 \mu \mathrm{m}$ and PEG6000 seemed to be smooth surface particles with a crystalline-amorphous surface. 

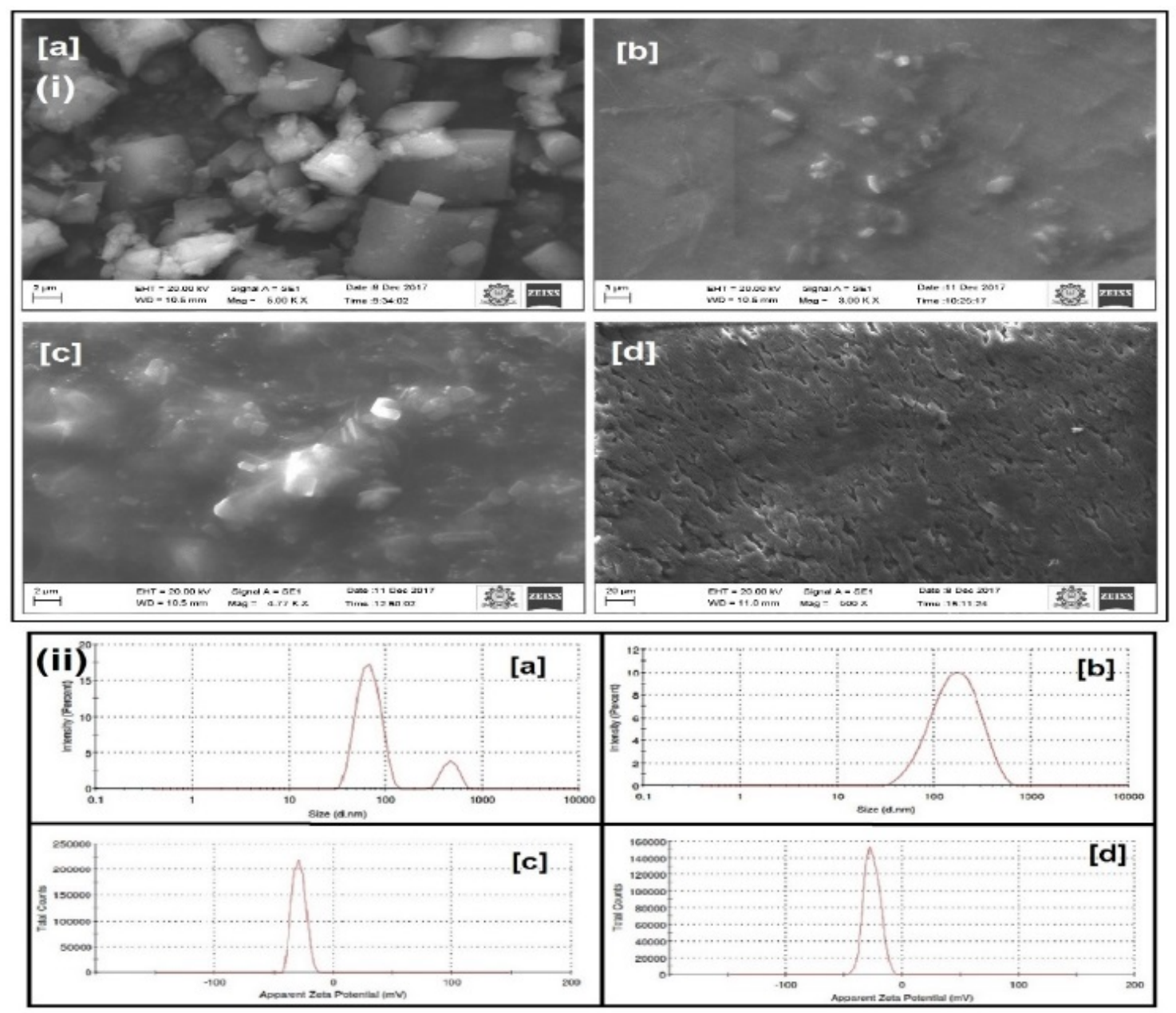

Figure 6 SEM image (i); CMN (a), PEG6000 (b), CMN-PM (c) and CMN-SD (d) and DLS (ii); CMNPM and SD with PEG6000; particle size of CMN-PM (a), CMN-SD (b), the ZP of CMN-PM (c) and CMN-SD (d).

In the topological changes perceived in the drug particles of the $\mathrm{SD}$, the drug surface seems to be more porous and was observed to be uniform and homogeneously dispersed (morphology of both the CMN and PEG6000 had disappeared) at the molecular level. This resulted as CMN was completely converted into the amorphous state.

\section{DLS}

The hydrodynamic PS of CMN-PM was found to be $235 \pm 3 \mathrm{~nm}$ with a PDI of 0.286 (Figure 6 ii; a) revealed as a bi-modal size distribution (presence of at least 2 constituents) in the solution of the PM. The hydrodynamic diameter of CMN-SD was $144.6 \pm 5 \mathrm{~nm}$ with a PDI of 0.236 (Figure 6 ii; b). ZP is a dynamic parameter to study the nature of the particle surface and predict long-term stability. The ZP of PM and SD was found to be -26.1 and $-29.3 \mathrm{mV}$ (Figure 6 ii; c and d), respectively, and it shows that the surface charge was reduced to some extent. The report revealed a low PDI indicating the uniformity of particle size distribution, and CMN-PEG6000 SD has enough repulsive force to prevent aggregation during long-term storage due to conversion into amorphous form [29].

\section{Dyeing effect}

As shown in Figure 7(a), CMN, CMN-PEG6000 SD (1:5) and CMN-PEG4000 SD (1:5), when 10 $\mathrm{mg} \mathrm{CMN}$ was added to $15 \mathrm{~mL}$ of water, CMN floated on the water because of its lipophilic state. However, the mixture was clear and its characteristic transparent with SDs of PEG6000. Subsequently, PEG4000 is shown as the yellow colour suspension when it was added to the same volume of water. The dyeing effects indicate that the solubilising capacity is predominant in CMN-PEG6000 SD (Figure 7(b)). 


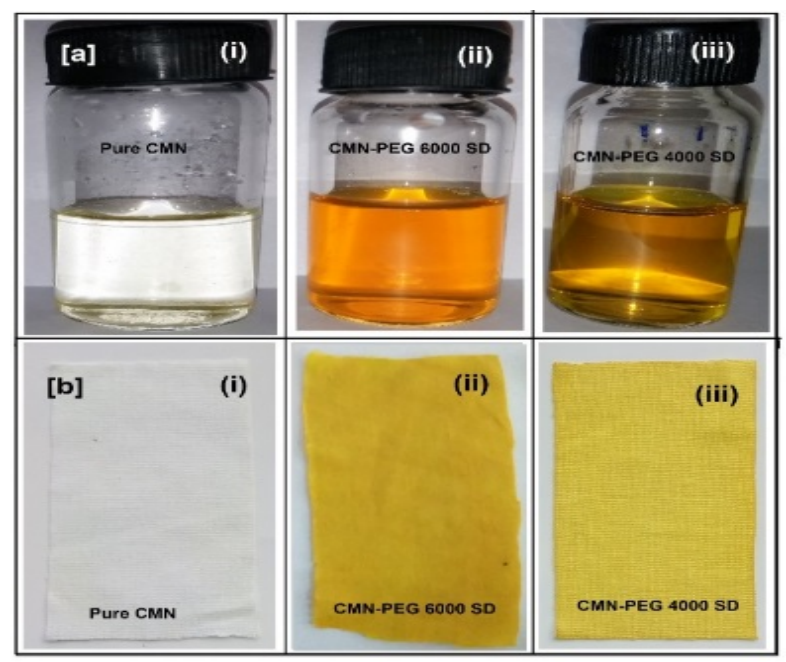

Figure 7 Photograph of solution (a); CMN (i), CMN-PEG6000 SD (ii) and CMN-PEG4000 SD (iii) and photograph of cotton clothes dyed in the solution (b); CMN (i), CMN-PEG6000 SD (ii) and CMNPEG4000 SD (iii).

This simple functionalized dye test without auxiliaries showed that CMN-PEG6000 (SD) displayed better dyeing effect, indicating that the aqueous solubility of CMN increased more evenly in water after of PEG6000 [30].

\section{MTT assay}

Among all carriers, PEG6000 showing better physicochemical properties over the other. Subsequently we studied PEG6000 for cytotoxic contribution. The cytotoxic results of the MTT-reduction assay of pure CMN and CMN-PEG6000 (SD) on SW480 (Figure 8(a)) and Caco-2 (Figure 8(b)) cells lines are shown in Figure 8. The $\mathrm{IC}_{50}$ value for $\mathrm{SD}$ was found to be between 72 and $40 \mu \mathrm{m} / \mathrm{mL}$, while that of pure CMN ranged from 146 to $116 \mu \mathrm{m} / \mathrm{mL}$ after $24 \mathrm{~h}$ treatment.

The results from the MTT assay revealed better cytotoxic activity than pure CMN. These findings could be because of the effect of the variations in the cellular uptake profile leading to better action of SD as suggested by Manju and coworker [31]. The results of this assay indicate that complex of SD can efficiently deliver the drug to SW480 and Caco-2 cells using active targeting by the endocytic process with improved cytotoxicity and aqueous solubility of CMN-SD. The cell viability with both SD and pure $\mathrm{CMN}$ decreases with increasing concentration of cytotoxicity, whereas SD was significantly better than that of native CMN.
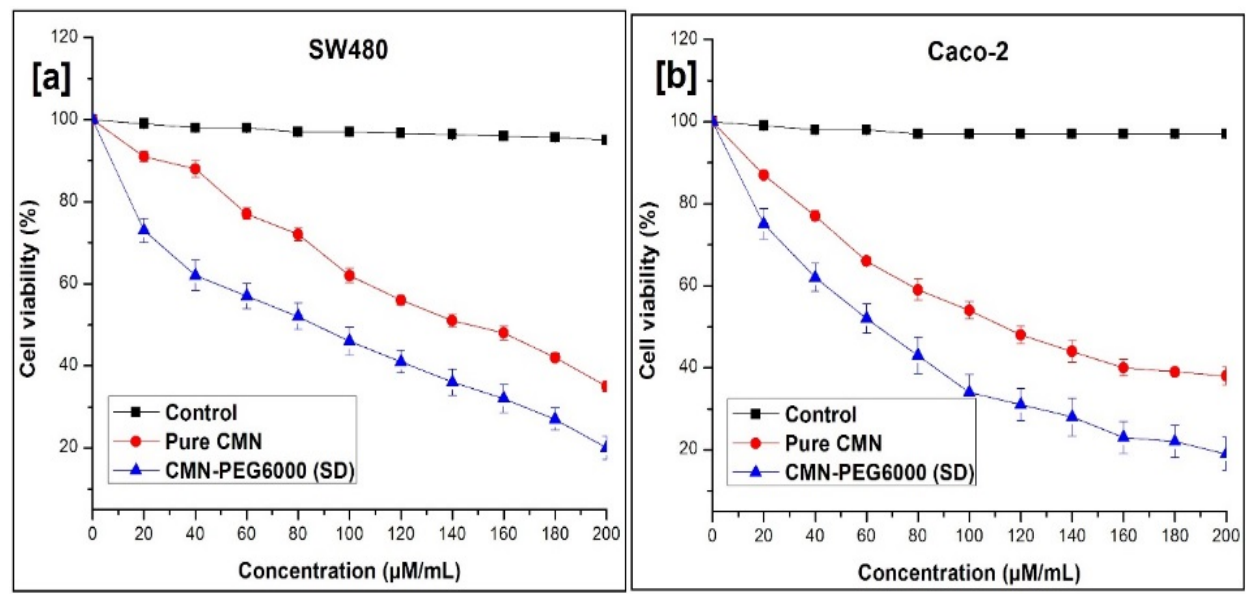

Figure 8 In vitro cytotoxic effect of CMN and CMN-PEG6000 SD on SW480 (a) and Caco-2 cells lines (b). (Mean $\pm \mathrm{SD}, \mathrm{n}=3$ ). 


\section{Apoptosis study by AO/EB staining}

The morphology of control or viable cells that appear in a bright green colour and having uniform chromatin with an intact cell membrane showing they did not undergo any apoptotic changes (Figures 9(a) and 9(c)). The stained cells characterized by SD caused more effective cell death than free CMN. Several non-viable cells and necrosis mode of cell death were also seen in both samples (Figure 9(e)). Morphological changes during cell death are essential criteria in apoptosis that can be measured by $\mathrm{AO} / \mathrm{EB}$ staining [32]. Collectively, if the cells underwent a specific pattern of cell death, cytological changes would have been observed by $\mathrm{AO} / \mathrm{EB}$ staining. As indicated by the fluorescence emission and geologies of the chromatin, cells can be characterized into the following types: viable cells - these have very uniform and sorted out structures with green fluorescing cores (Figures 9a and $\mathbf{b}$; i); early apoptotic cells - these have intact membranes with green fluorescing cores, yet fragmentation of DNA was seen to have started and chromatin buildup was peri nuclear and visible in splendid green pieces or patches (Figures 9a and b; ii and iii); late apoptotic cells - these had divided or condensed chromatin with orange to red fluorescing cores (Figures 9a and b; ii and iii); and necrotic cells - these have substantial or swollen structures and consistently orange to red fluorescing nucleii with the non-appearance of chromatin fragmentation (Figures 9a and b; ii and iii) [33]. These results imply that CMN-SD complex treatment caused cell death through apoptosis and necrosis.

\section{Apoptosis study by Hoechst 33528 staining}

After treatment with $\mathrm{IC}_{50}$ concentrations of the complexes for $24 \mathrm{~h}$, the SW480 and Caco-2 cells were observed for cytological changes. The manual count of normal and abnormal, that is, apoptotic cells was obtained in percentage from the Hoechst 33258 staining in SW480 and Caco-2 cells and shown in Figures 9(c) and 9(d). Altogether, a higher level of apoptotic cell death of SW480 and Caco-2 was detected in contrast to necrotic cell death (Figure 9(e)) than in the case of free CMN treatment. Hoechst staining revealed the deviations in cytology of the cell, with special reference to the cytoplasm and nucleus core at primary level identifying the apoptosis. The CMN-SD observation showed that the early apoptotic highlights, such as cell shrinkage, chromatin buildup, and discontinuity had been seen in treated cells and small quantities of necrotic cells [34] were also observed.

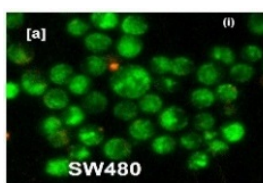

Control
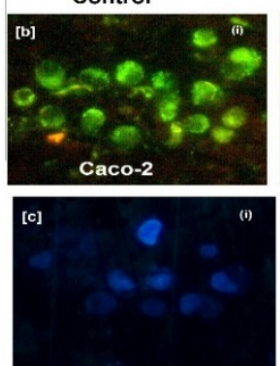

Control

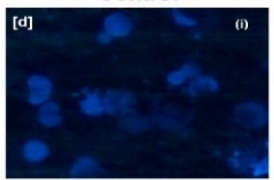

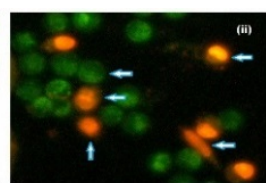

Pure CMN
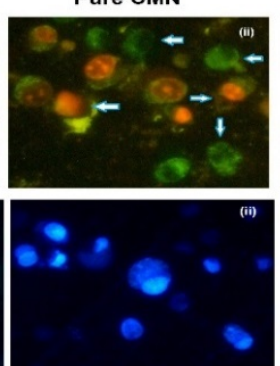

Pure CMN

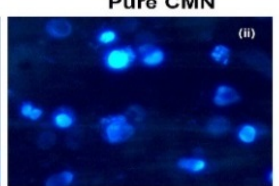

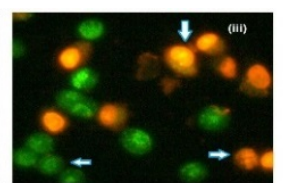

CMN-PEG600 (SD)
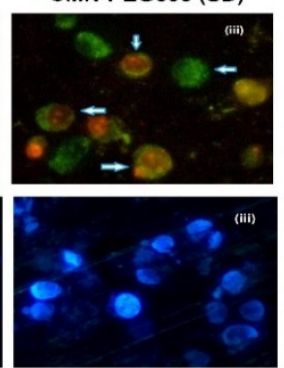

CMN-PEG600

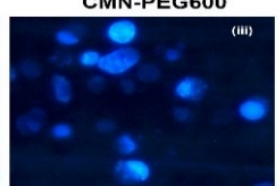

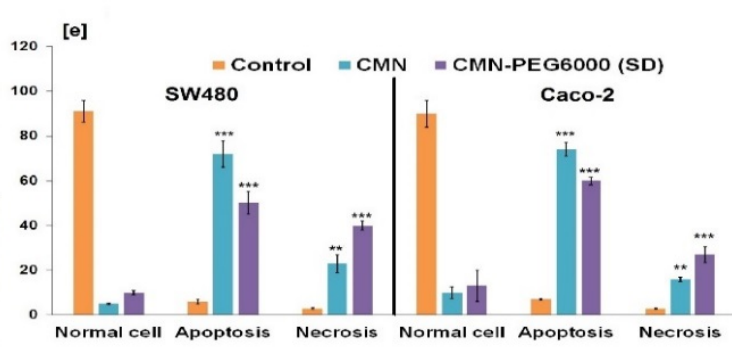

Figure 9 Apoptotic morphology of $\mathrm{AO} / \mathrm{EB}$ and Hoechst 33258 staining visualized under fluorescent microscope with SW480 (a and c), Caco-2 cells (b and d); control (i), pure CMN (ii) and CMN-SD (iii) and percentage of normal, apoptotic and necrotic cells after $24 \mathrm{~h}$ treatment (e). Significant differences compared to control are indicated by $* * * p<0.001$ and $* * p<0.05$, both calculated by the student t-test. 


\section{Conclusions}

This study attempted to analyze the solubility and dissolution properties of the curcumin complex with various carriers and evaluated the anticancer potency of soluble curcumin on the colorectal adenocarcinoma cell lines of SW480 and Caco-2. The profound efficiency of soluble curcumin indicated its potential application for CRC treatment. The research provided an existing and novel method for the implementation of a valuable cancer therapy. We hope the present investigation will inspire further work along these lines.

\section{Acknowledgements}

The author directly acknowledges gratefully the National Institute of Technology, Tiruchirappalli.

\section{References}

[1] NC Hall and AT Ruutiainen. Colorectal cancer: Imaging conundrums. Surg. Oncol. Clin. N Am. 2018; 27, 289-302.

[2] A Farinetti, V Zurlo, A Manenti, F Coppi and AV Mattioli. Mediterranean diet and colorectal cancer: A systematic review. Nutrition 2017; 43-44, 83-8.

[3] MK John, H Xie, EC Bell and D Liang. Development and pharmacokinetic evaluation of curcumin co-solvent formulation. Anticancer Res. 2013; 33, 4285-91.

[4] SS Bansal, M Goel, F Aqil, MV Vadhanam and RC Gupta. Advanced drug delivery systems of curcumin for cancer chemoprevention. Cancer Prev. Res (Phila) 2011; 4, 1158-71.

[5] T Higuchi and KA Connors. Phase solubility techniques. Adv. Anal. Chem. Instrum. 1965; 4, 117212.

[6] C Nicolescu, CC Arama, A Nedelcu and CM Monciu. Phase solubility studies of the inclusion complexes of repaglinide with $\beta$-cyclodextrin and $\beta$-cyclodextrin derivatives. Farmacia 2010; 58, $620-8$.

[7] MMJ Moideen, A Alqahtani, K Venkatesan, F Ahmad, K Kalpana, M Gayasuddin, RA Shaik, KMM Ibraheem, MEDM Salama and SY Abed. Application of the Box-Behnken design for the production of soluble curcumin: Skimmed milk powder inclusion complex for improving the treatment of colorectal cancer. Food Sci. Nutr. 2020; 8, 6643-59.

[8] A Almeida, S Possemiers, MN Boone, TD Beer, T Quinten, LV Hoorebeke, JP Remon and C Vervaet. Ethylene vinyl acetate as a matrix for oral sustained release dosage forms produced via hot-melt extrusion. Eur. J. Pharm. Biopharm. 2011; 77, 297-305.

[9] MJ Muthu, K Kavitha, KS Chitra and S Nanthineeswari. Soluble curcumin prepared using four different carriers by solid dispersions: Phase solubility, molecular modelling and physicochemical characterization. Trop. J. Pharm. Res. 2019; 18, 1581-8.

[10] MMJM Moideen, K Karuppaiyan, R Kandhasamy and S Seetharaman. Skimmed milk powder and pectin decorated solid lipid nanoparticle containing soluble curcumin used for the treatment of colorectal cancer. J. Food Process Eng. 2019; 43, e13246.

[11] NS Kumar, M Ganapathy, S Sharmila, M Shankar, M Vimalan and IV Potheher. ZnO/Ni(OH)2 core-shell nanoparticles: Synthesis, optical, electrical and photoacoustic property analysis. J. Alloys Compd. 2017; 703, 624-32.

[12] L Liu, J Xu, H Zheng, K Li, W Zhang, K Li and H Zhang. Inclusion complexes of laccaic acid A with $\beta$-cyclodextrin or its derivatives: Phase solubility, solubilization, inclusion mode, and characterization. Dyes Pigm. 2017; 139, 737-46.

[13] JM Mohamed, A Alqahtani, F Ahmad, V Krishnaraju and K Kalpana. Pectin co-functionalized dual layered solid lipid nanoparticle made by soluble curcumin for the targeted potential treatment of colorectal cancer. Carbohydr. Polym. 2021; 252, 117180.

[14] S Karthik, R Sankar, K Varunkumar and V Ravikumar. Romidepsin induces cell cycle arrest, apoptosis, histone hyperacetylation and reduces matrix metalloproteinases 2 and 9 expression in bortezomib sensitized non-small cell lung cancer cells. Biomed. Pharmacother. 2014; 68, 327-34.

[15] R Iacovino, JV Caso, F Rapuano, A Russo, M Isidori, M Lavorgna, G Malgieri and C Isernia. Physicochemical characterization and cytotoxic activity evaluation of hydroxymethyl ferrocene: $\beta$ cyclodextrin inclusion complex. Molecules 2012; 17, 6056-70.

[16] M El-Badry. Physicochemical characterization and dissolution properties of meloxicam-gelucire 50/13 binary systems. Sci. Pharm. 2011; 79, 375-86. 
[17] W Ali, AC Williams and CF Rawlinson. Stochiometrically governed molecular interactions in drug: Poloxamer solid dispersions. Int. J. Pharm. 2010; 391, 162-8.

[18] AB Gangurde, HS Kundaikar, SD Javeer, DR Jaiswar, MS Degani and PD Amin. Enhanced solubility and dissolution of curcumin by a hydrophilic polymer solid dispersion and its In-silico molecular modeling studies. J. Drug Deliv. Sci. Technol. 2015; 29, 226-37.

[19] CS Mangolim, C Moriwaki, AC Nogueira, F Sato, ML Baesso, AM Neto and G Matioli. Curcumin$\beta$-cyclodextrin inclusion complex: Stability, solubility, characterisation by FT-IR, FT-Raman, X-ray diffraction and photoacoustic spectroscopy, and food application. Food Chem. 2014; 153, 361-70.

[20] M Palanisamy and J Khanam. Solid dispersion of prednisolone: Solid state characterization and improvement of dissolution profile. Drug Dev. Ind. Pharm. 2011; 37, 373-86.

[21] F Sadeghi, M Ashofteh, A Homayouni, M Abbaspour, A Nokhodchi and HA Garekani. Antisolvent precipitation technique: A very promising approach to crystallize curcumin in presence of polyvinyl pyrrolidon for solubility and dissolution enhancement. Colloids Surf. B Biointerfaces 2016; 147, 258-64.

[22] J Li, I Lee, GH Shin, X Chen and HJ Park. Curcumin-Eudragit ${ }^{\circ}$ E PO solid dispersion: A simple and potent method to solve the problems of curcumin. Eur. J. Pharm. Biopharm. 2015; 94, 322-32.

[29] UMD Lekshmi, G Poovi, N Kishore and PN Reddy. In vitro characterization and in vivo toxicity study of repaglinide loaded poly (methyl methacrylate) nanoparticles. Int. J. Pharm. 2010; 396, 194-203.

[24] F Kurniawansyah, L Quachie, R Mammucari and NR Foster. Improving the dissolution properties of curcumin using dense gas antisolvent technology. Int. J. Pharm. 2017; 521, 239-48.

[25] SJ George and DT Vasudevan. Characterization, and solubility of 2-HP-ß-Cyclodextrin-Meclizine $\mathrm{HCl}$ inclusion complexes. J. Young Pharm. 2012; 4, 220-7.

[26] AA Thorat and SV Dalvi. Solid-state phase transformations and storage stability of curcumin polymorphs. Cryst. Growth Des. 2015; 15, 1757-70.

[27] M Khairuddin, E Pramono, SB Utomo, V Wulandari, WA Zahrotul and F Clegg. The effect of polyethylene glycol Mw 400 and 600 on stability of Shellac Waxfree. J. Phys. Conf. Ser. 2016; 776, 1757-8981.

[28] A Popat, S Karmakar, S Jambhrunkar, C Xu and C Yu. Curcumin-cyclodextrin encapsulated chitosan nanoconjugates with enhanced solubility and cell cytotoxicity. Colloids Surf. B Biointerfaces 2014; 117, 520-7.

[29] CS Kumar, A Mahesh, MG Antoniraj, S Vaidevi and K Ruckmani. Ultrafast synthesis of stabilized gold nanoparticles using aqueous fruit extract of Limonia acidissima $L$ and conjugated epirubicin: Targeted drug delivery for treatment of breast cancer. $R S C A d v .2016 ; 32,26874-82$.

[30] S Xu, J Chen, B Wang and Y Yang. Sustainable and hydrolysis-free dyeing process for polylactic acid using nonaqueous medium. ACS Sustain. Chem. Eng. 2015; 3, 1039-46.

[31] S Manju and K Sreenivasan. Gold nanoparticles generated and stabilized by water soluble curcumin-polymer conjugate: Blood compatibility evaluation and targeted drug delivery onto cancer cells. J. Coll. Inter. Sci. 2012; 368, 144-51.

[32] SDA Abel and SK Baird. Honey is cytotoxic towards prostate cancer cells but interacts with the MTT reagent: Considerations for the choice of cell viability assay. Food Chem. 2018; 241, 70-8.

[33] R Dhivya, P Jaividhya, A Riyasdeen, M Palaniandavar, G Mathan and MA Akbarsha. In vitro antiproliferative and apoptosis-inducing properties of a mononuclear copper(II) complex with dppz ligand, in two genotypically different breast cancer cell lines. Biometals 2015; 28, 929-43.

[34] G Vignesh, R Senthilkumar, P Paul, VS Periasamy, MA Akbarsha and S Arunachalam. Protein binding and biological evaluation of a polymer-anchored cobalt(III) complex containing a 2,2bipyridine ligand. $R S C A d v$. 2014; 4, 57483-92. 